\title{
Desenvolvimento de biscoitos, tipo salgado, enriquecidos pela adição de merluza
}

\author{
Development of biscuits enriched with merluza
}

\author{
Niurka Maritza Almeyda HAJ-ISA ${ }^{1 *}$, Elisangela Silva CARVALHO ${ }^{2}$
}

\begin{abstract}
Resumo
O uso de espécies de pescado de baixo valor comercial ou de subprodutos de sua industrialização constitui-se em alternativa promissora para a elaboração de produtos alimentícios economicamente viáveis e de alta qualidade nutricional. Foram elaborados biscoitos substituindo-se farinha de trigo por carne de merluza (22,5 e 27\%). Foram realizadas determinações de umidade, cinzas e microbiológica, além de calculados os principais parâmetros nutricionais. A aceitação e a preferência sensorial foram julgadas por 45 provadores. A elaboração de biscoitos adicionados de merluza foi considerada tecnologicamente viável e com características químicas, microbiológicas e sensoriais satisfatórias. Os biscoitos com 22,5\% do pescado tiveram maior preferência entre os consumidores. O menor aporte energético dos biscoitos formulados com merluza, a melhor qualidade proteica, o aumento do conteúdo de minerais e a benéfica composição lipídica dessa matéria-prima fazem dos biscoitos produzidos uma boa alternativa nutricional para merendas e complemento de lanches.
\end{abstract}

Palavras-chave: bolacha; pescado; nutrição.

\begin{abstract}
Low cost fish species and fish industry by-products are promising alternatives for the elaboration of economically viable products with high nutritional quality. We elaborated biscuits replacing part of the wheat flour in the basic recipe with merluza flesh (22.5 and $27 \%$ ). Moisture, ashes, microbiological characteristics, and the main nutrition values were determined. The acceptance and sensorial preference were judged by 45 panelists. Merluza biscuit was considered technologically viable and had adequate chemical, microbiological, and sensory characteristics. The product with $22.5 \%$ of fish was preferred by the panelists. The lower energy value combined with the higher protein, the mineral contents, and the advantageous unsaturated fat composition of our product make it a good nutritional alternative for snacks.
\end{abstract}

Keywords: cookies; fish; nutrition.

\section{Introdução}

Em toda a extensão territorial do Brasil, percebem-se hábitos alimentares diversificados, sendo que a maior parte da população tem como base alimentar arroz, fubá, farinha de mandioca e açúcar; estes são importantes fontes calóricas, mas insuficientes para fornecer os outros macronutrientes e alguns micronutrientes essenciais às funções do organismo humano (GUILHERME; JOKL, 2005).

Segundo dados da Secretaria Especial de Aquicultura e Pesca (SEAP), o consumo de peixe no Brasil ainda está abaixo do recomendado pela Organização Mundial de Saúde (OMS). O brasileiro consome $8 \mathrm{~kg}$ por ano, enquanto a média mundial é exatamente o dobro disso (POMPEU, 2008); note-se que a OMS recomenda como ideal o consumo anual de $12 \mathrm{~kg}$ por pessoa (RODRIGUES, 2007).

O pescado, bem como a carne de pescado mecanicamente separada, contêm baixo teor de colesterol LHL, são ricos em ácidos graxos poli-insaturados (tipo Ômega 3) e importantes na prevenção de doenças cardiovasculares e para o desenvolvimento de células cerebrais no feto e nos recém-nascidos. $\mathrm{O}$ pescado ainda oferece minerais, principalmente cálcio e fósforo, vitaminas A, D e do complexo B, o que o torna um produto de alto valor nutricional (SUZUKI, 1987; HALL, 1992; RANKEN, 1993; SIMÕES et al., 2004; VILA NOVA; GODOY; ALDRIGUE, 2005).

Essa matéria-prima é fonte de proteínas de alto valor biológico por causa da quantidade mínima de tecido conjuntivo; estas são altamente sensíveis à hidrólise, ou seja, de alta digestibilidade, e possuem composição balanceada de aminoácidos, geralmente ricos em metionina e cisteína, aminoácidos limitantes de muitos alimentos (BÁRZANA; GARIBAY-GARCÍA, 1994).

Dentre os produtos de origem animal, os peixes são os mais suscetíveis a processos de deterioração, o que pode ser explicado pela sua composição química, pela elevada insaturação de seus lípides, pela menor quantidade de tecido conjuntivo, em consequência da ação de enzimas autolíticas, e pela relação menos ácida de sua carne, o que favorece o crescimento microbiano (NEIVA, 2005).

${ }^{1}$ Tecnologia de Alimentos, Fundação Tropical de Pesquisas e Tecnologia André Tosello - FTPTAT, Rua Latino Coelho, 1301, CEP 13820-000, Campinas - SP, Brasil, E-mail: professoraniurka@hotmail.com

2 Departamento de Nutrição, Faculdade de Jaguariúna - FAJ, Rua Amazonas, 504, Jardim Dom Bosco, CEP 13820-000, Jaguariúna - SP, Brasil, E-mail: nutrição@faj.br ${ }^{*}$ Corresponding author 
A alta perecibilidade do pescado tem estimulado a aplicação de tecnologias alternativas de conservação muito importantes (NEIVA, 2008). A oferta e a diversificação de produtos derivados de pescado poderão incrementar o consumo dessa importante matéria-prima.

De acordo com o presidente do Sindicato da Indústria de Massas Alimentícias e Biscoitos do Estado de São Paulo (SIMABESP), a indústria de biscoitos brasileira se posiciona como a segunda maior produtora mundial, com produção de 1,2 milhão de toneladas em 2009 , um crescimento de $2,5 \%$ em volume com relação a 2008 (REIS, 2009). Exporta para mais de 118 países, atingindo uma cifra de US\$ 91,61 milhões, e tem como desafio para 2008 incrementar as vendas externas em $10 \%$ (REIS, 2008).

No Brasil, grande número de fabricantes produz biscoitos para crianças e adultos, populares ou finos, convencionais ou light, doces ou salgados, sendo que os principais diferenciais entre as marcas são a qualidade, o preço e a apresentação. Este potencial, unido à grande aceitação desses produtos por pessoas de todas as faixas etárias - sendo a média per capita no país de $6,3 \mathrm{~kg}$ por ano (REIS, 2009) -, assim como os resultados obtidos em pesquisas anteriores (PEREZ; GERMANI, 2007; NEIVA, 2008), estimulam o estudo do biscoito como veículo de proteínas e outros nutrientes derivados de pescados.

Bolacha de pescado é um produto preparado com carne moída fresca ou congelada, tanto de pescado marinho (incluídas as espécies de carne vermelha e branca) quanto de água doce, mariscos e moluscos (lagostins, camarões, lulas, ostras, mexilhões etc.), cuja preparação básica inclui mistura de ingredientes, modelagem, assamento, esfriamento e embalagem em material impermeável à umidade e a gases, que evite a oxidação durante o armazenamento (FOOD..., 2001).

Considerando-se estes antecedentes, o presente trabalho objetivou desenvolver biscoitos caseiros tipo salgado, adicionados de pescado de baixo custo ou baixa aceitação sensorial, assim como avaliar o efeito da substituição de ingredientes básicos por carne de pescado na qualidade dos biscoitos.

\section{Material e métodos}

\subsection{Matéria-prima}

$\mathrm{Na}$ elaboração dos biscoitos, utilizaram-se como ingredientes farinha de trigo, carne de pescado úmida, amido de milho, margarina $60 \%$ (free trans), água, açúcar, gema de ovo in natura, sal, condimentos e fermento químico em pó.

Visando conhecer aceitação de espécies de pescado comercializadas em três supermercados das cidades de Campinas e Jaguariúna, ambas localizadas no Estado de São Paulo, Brasil, foi realizada uma pesquisa de campo com 105 clientes. Posteriormente à avaliação dos resultados, carne de merluza (Merlucius hubbsi) e carne de pescada (Macrodon ancylodon) foram escolhidas para adição nas formulações de biscoitos por serem variedades de pescados de baixa aceitação, mesmo que o preço destas no varejo esteja entre os mais baixos no setor de peixes.

Quatro produtos (filés de merluza e pescada com ou sem pele), de três marcas distintas de produtores de pescado congelado (A, B, C), foram inicialmente avaliados, em triplicata, em relação ao rendimento para aproveitamento da carne a ser adicionada nas formulações de biscoitos.

Os pescados e todos os ingredientes utilizados (Tabela 1) foram adquiridos na rede pública de supermercados da cidade de Campinas-SP.

\subsection{Testes preliminares}

Após verificar o rendimento dos diferentes produtos de pescado e utilizando-se como base uma receita caseira de biscoito salgado, diversos testes preliminares foram realizados, substituindo-se parcialmente o conteúdo de farinha de trigo por carne de merluza sem pele e variando a proporção de alguns ingredientes. Os testes visaram principalmente definir a espessura dos biscoitos, tempo e temperatura do assamento e aspectos sensoriais do produto final (crocância e sabor).

Tabela 1. Ingredientes das formulações.

\begin{tabular}{|c|c|c|c|c|}
\hline \multirow[t]{3}{*}{ Ingrediente } & \multicolumn{4}{|c|}{ Formulação } \\
\hline & \multicolumn{2}{|c|}{1} & \multicolumn{2}{|c|}{2} \\
\hline & (g) & $(\%)$ & (g) & $(\%)$ \\
\hline Merluza & 54 & 27,0 & 45 & 22,5 \\
\hline Farinha trigo & 45 & 22,5 & 45 & 22,5 \\
\hline Maisena & 35 & 17,5 & 38 & 19,0 \\
\hline Margarina (free trans, $60 \%$ lip) & 30 & 15,0 & 40 & 20,0 \\
\hline Água & 20 & 10,0 & 20 & 10,0 \\
\hline Açúcar & 4 & 2,0 & 4 & 2,0 \\
\hline Gema de ovo (in natura) & 4 & 2,0 & 0 & 0 \\
\hline Fermento químico em pó & 4 & 2,0 & 4 & 2,0 \\
\hline Sal & 2 & 1,0 & 2 & 1,0 \\
\hline $\begin{array}{l}\text { Mistura de condimentos secos: } 1,5 \mathrm{~g} \text { tempero } \\
\text { alho e } 0,50 \mathrm{~g} \text { de manjericão desidratado }\end{array}$ & 2 & 1,0 & 2 & 1,0 \\
\hline Peso total & 200 & 100 & 200 & 100 \\
\hline
\end{tabular}




\subsection{Elaboração dos biscoitos}

Foram desenvolvidas duas formulações de biscoitos (Figura 1; Tabela 1), tendo como requisito manter condições caseiras para sua elaboração, isto é, sem inclusão de ingredientes não disponíveis no mercado varejista e etapas de elaboração que exijam equipamentos diferentes aos comumente disponíveis em casa (fogão de quatro bocas com forno, mesa e utensílios culinários).

A adição de gema de ovo na formulação 1 foi devida aos resultados nos testes preliminares, nos quais provadores relataram gosto de ovo no biscoito associado à melhor textura. Assim, foi decidido diminuir a quantidade de gema e novamente testar a formulação com esse ingrediente.

\subsection{Caracterização dos biscoitos}

Os produtos finais obtidos foram avaliados por meio de:

- Caracterização física: 10 unidades de cada produto foram utilizadas para avaliar a perda de peso dos biscoitos, que foi determinada pela variação do peso antes e depois do assamento. O diâmetro e a altura dos biscoitos foram aferidos com paquímetro;

- Análises bromatológicas: foram determinados, em triplicata, os teores de cinzas e de umidade, pelos métodos de mufla e de estufa, respectivamente (BRASIL, 2005). O valor calórico dos biscoitos e as quantidades de proteína, lipídios, fibra e carboidrato foram estimados a partir das tabelas de composição de alimentos (UNIVERSIDADE..., 2006) e das declarações em rótulos dos fabricantes das matérias-primas utilizadas;

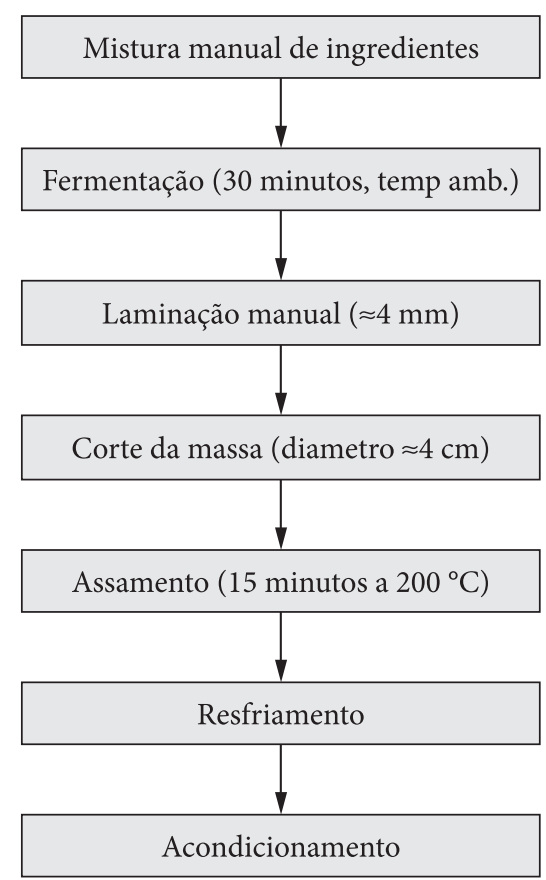

Figura 1. Fluxograma de produção do biscoito salgado caseiro com pescado.
- Análises microbiológicas: a análise microbiológica dos biscoitos foi realizada pelo método de Vandervant e Splippspoesser (1992), constando da contagem dos seguintes micro-organismos: coliformes totais, coliformes fecais, bolores e leveduras. Os resultados foram comparados com os estipulados pela Portaria $n^{\circ} 451$ de 19 de setembro de 1997, da Secretaria Nacional de Vigilância Sanitária (BRASIL, 1998); e

- Análise sensorial: foi aplicado um teste afetivo de aceitação e preferência pareada (MEILGAARD et al., 1991), com 45 potenciais consumidores do produto, ou seja, indivíduos que gostam de biscoito salgado e de pescado.

\subsection{Estimativa de custo dos biscoitos}

Para estimar o custo médio das duas formulações, foram levados em consideração os valores das matérias-primas utilizadas para venda ao consumidor em cinco mercados (dois na cidade de Jaguariúna-SP e três em Campinas-SP).

\subsection{Análise de resultados}

Os resultados foram estatisticamente avaliados por análise de variância (ANOVA), sendo determinada a significância estatística das diferenças entre as médias por meio do teste de Tukey, para o nível de significância $\mathrm{p}<0,05$.

\section{Resultados e discussão}

O valor agregado em produtos de pescado não deve necessariamente estar vinculado à elaboração de produtos sofisticados e modernos, mas sim prioritariamente à qualidade intrínseca do pescado ou matéria-prima utilizada (NEIVA, 2005).

Os pescados analisados, embora de boa qualidade nutricional, apresentam baixo valor comercial, pois não é muito adequado para filetagem devido ao alto número de espinhas (BÁRZANA; GARIBAY-GARCÍA, 1994), o que também justifica uma baixa aceitação por parte dos consumidores. A merluza sem pele utilizada (marca $\mathrm{C}$ ) apresentou o menor rendimento de aproveitamento, diferindo estatisticamente das outras marcas avaliadas (Tabela 2).

Centenaro et al. (2003), na elaboração de pães com carne de pescado, utilizaram peixes classificados como "mistura" (peixes que aparecem na pesca direcionada ao camarão e a outras espécies marinhas), composta por espécies da família da pescada (perna-de-moça e castanha) e de outras famílias (castanha, cabrinha, carapau e guaivira). Esses pesquisadores obtiveram rendimentos de $34 \%$ na polpa úmida e de 31,6\% no filé moído, inferiores aos obtidos nesta pesquisa para qualquer das espécies ensaiadas (Tabela 2). Esse fato pode ser explicado por terem sido utilizados, neste trabalho, pescados já processados, ficando apenas as perdas relativas ao descongelamento.

Pesquisas realizadas pelo Instituto de Pesos e Medidas do Estado de São Paulo (IPEM-SP), em 2005, 2006 e 2007, mostraram diversas irregularidades referentes a pescados congelados, sendo o quesito peso do alimento em si, desconsiderando a água 
Tabela 2. Rendimento de filé de pescado após descongelamento.

\begin{tabular}{|c|c|c|c|c|c|}
\hline Pescado & Marca & $\begin{array}{c}\text { Peso inicial } \\
(\mathrm{g})\end{array}$ & $\begin{array}{l}\text { Peso final } \\
(\mathrm{g})\end{array}$ & $\begin{array}{c}\text { Itens considerados } \\
\text { perda }\end{array}$ & $\begin{array}{c}\text { Rendimento } \\
(\%)^{*}\end{array}$ \\
\hline $\begin{array}{l}\text { Merluza } \\
\text { (Merlucius hubbsi) }\end{array}$ & A & 250 & 172 & $\begin{array}{l}\text { água, pele e } \\
\text { espinhas }\end{array}$ & $68,8^{a}$ \\
\hline $\begin{array}{l}\text { Pescada } \\
\text { (Macrodon ancylodon) }\end{array}$ & & 250 & 183 & & $73,2^{\mathrm{a}}$ \\
\hline Merluza & B & 340 & 234 & & $68,8^{\mathrm{a}}$ \\
\hline Merluza sem pele & $\mathrm{C}$ & 500 & 246,1 & $\begin{array}{l}\text { água e espinhas } \\
\text { (poucas) }\end{array}$ & $49,2^{\mathrm{b}}$ \\
\hline
\end{tabular}

${ }^{\star}$ Letras diferentes assinalam diferenças estatísticas $(\mathrm{p}=0,0410)$ - ANOVA, teste de Tukey.

existente dentro deles e a do glaceamento, o de maior distorção (SÃO PAULO..., 2007).

\subsection{Biscoitos tipo salgados com pescado}

O biscoito é um produto alimentício obtido pelo amassamento e pelo cozimento conveniente de massa preparada com farinha, amidos, féculas e outras substâncias alimentícias, fermentado ou não (ACORSI et al., 2009). Conforme fluxograma apresentado, foi possível obter duas formulações de biscoitos caseiros com pescados (Figura 2).

Não houve diferenças estatisticamente significativas na variação de peso das formulações 1 e 2 durante o processo de assado (média $=39,9 \%$ ), independentemente de a formulação 1 conter maior quantidade de proteína em função da adição de gema de ovo junto a $5 \%$ a mais de pescado. Igual comportamento foi observado nas medidas diâmetro e espessura das amostras $(\mathrm{p}<0,05)$, parâmetros importantes na avaliação de rendimento do produto, na avaliação da qualidade da matéria-prima empregada e para seu acondicionamento em embalagens padronizadas.

A avaliação nutricional estimada mostra teores de proteínas que satisfazem entre 5 e 7,5\% as necessidades diárias de um adulto (BRASIL, 2006). Embora a quantidade de proteína calculada nos formulados 1 e 2 (Tabela 3) seja inferior aos encontrados em biscoitos de marcas já estabelecidas no mercado, a qualidade dessas proteínas é certamente superior do ponto de vista da sua composição de aminoácidos essenciais, do grau de digestibilidade e do valor biológico (VILA NOVA et al., 2005).

Tem sido detectado na população um consumo muito elevado de proteína, contribuindo tal hábito para problemas renais, teores de ácido úrico elevado, entre outras consequências (GARCIA, 2003); portanto, partindo do princípio de que os biscoitos são alimentos de consumo habitual, a proporção proteica nos formulados pode ser vantajosa pela qualidade e pela menor quantidade, quando comparados aos biscoitos das marcas verificadas neste trabalho. Se fossem alimentos de consumo esporádico, não faria tanta diferença, mas bolachas e petiscos são consumidos diariamente por adultos e adolescentes, os quais também poderiam adquirir o hábito de comer indiretamente pescado, se beneficiando ainda da favorável composição lipídica dessa matéria-prima.

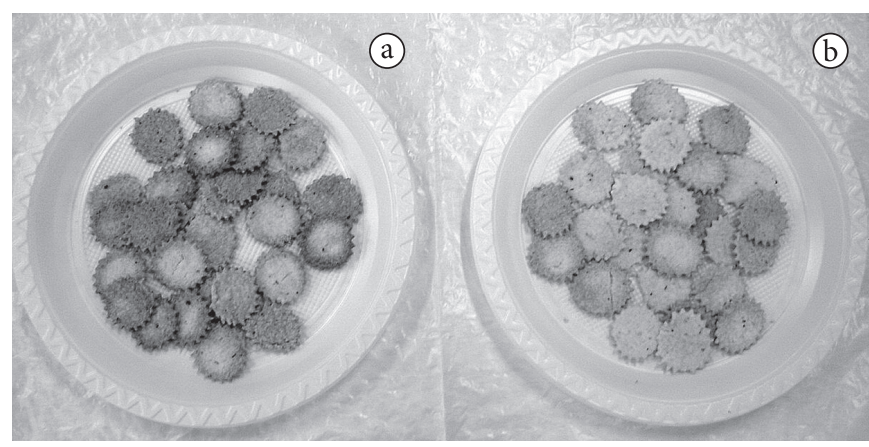

Figura 2. Biscoitos caseiros com merluza a) (27\%); e b) (22\%).

Os biscoitos, sem diferenças estatísticas entre as formulações $(\mathrm{p}<0,05)$, também apresentaram conteúdo de cinzas (média = 1,6 g.30 $\mathrm{g}^{-1}$ porção) $50 \%$ maior ao de biscoitos salgados, cream cracker em igual porção, correspondente a $0,81 \mathrm{~g}$ (UNIVERSIDADE..., 2006). Tal aumento de cinzas ocorre em razão de a merluza representar mais de $20 \%$ dos formulados e conter $27 \%$ de cinzas a mais do que a farinha de trigo (UNIVERSIDADE..., 2006), o que se traduz em maior aporte de minerais por meio dos biscoitos com pescado.

Outro aspecto a destacar é o menor aporte energético da porção sugerida dos biscoitos formulados em relação à igual porção dos outros biscoitos, o que constitui um elemento desejado por muitos consumidores preocupados em consumir alimentos menos energéticos, mas de boa qualidade nutricional.

$\mathrm{Na}$ compra de matérias-primas alimentícias e na fabricação de alimentos caseiros ou industrializados, os cuidados de higiene devem ser rigorosamente seguidos, incluindo-se pessoas que fabricam o produto, instalações, equipamentos, matéria-prima e embalagens utilizadas (VARGAS; QUINTAES, 2003).

Microbiologicamente, as duas formulações foram consideradas aptas para o consumo, pois não houve crescimento de coliformes totais, coliformes fecais, bolores e leveduras, denotando uma adequada qualidade microbiológica das matérias-primas utilizadas e boas práticas de manipulação durante a elaboração dos biscoitos.

Esses resultados, junto ao baixo valor de umidade das amostras (média $=3,82 \%$ sem diferenças estatísticas entre os formulados para $5 \%$ de probabilidade), podem favorecer as boas 
Tabela 3. Informação nutricional dos biscoitos desenvolvidos.

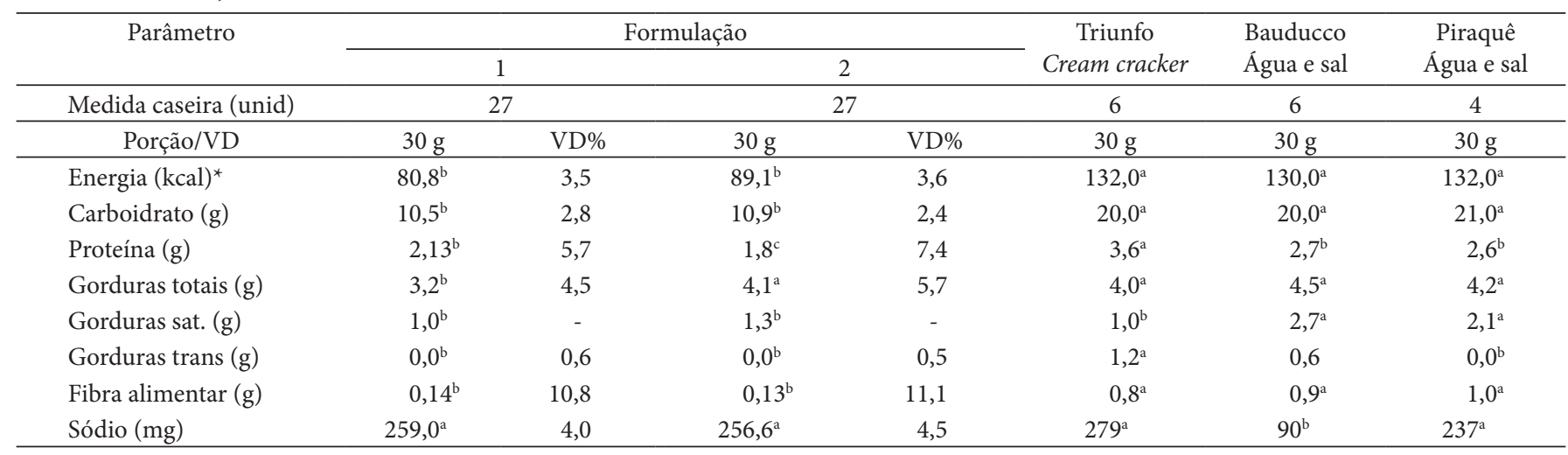

${ }^{\star}$ Letras diferentes, na horizontal, assinalam diferenças estatísticas $(p=0,0410)$ - ANOVA, teste de Tukey.

condições de vida-de-prateleira do produto, desde que este seja acondicionado em embalagem adequada, isto é, impermeável a umidade, gases e, preferivelmente, com barreira à luz.

Não houve diferenças estatisticamente significativas na aceitação dos biscoitos de pescado desenvolvidos $(\mathrm{p}<0,05)$. No entanto, no teste de preferência, houve diferenças entre as amostras, sendo o biscoito da formulação $2(22,5 \%$ de carne de merluza), o preferido. Mesmo com menor quantidade de merluza na composição, os provadores declararam que o biscoito da formulação 2 ficou com um sabor mais acentuado de pescado e uma maior crocância.

Centenaro et al. (2003) elaboraram cinco formulações de pães enriquecidos com pescado (30, 40 e $50 \%$ de polpa lavada úmida, e 3 e $5 \%$ de polpa lavada seca, em base à farinha). O pão com $5 \%$ de polpa seca foi considerado melhor pelos julgadores e não diferiu significativamente do padrão para nenhum atributo avaliado em teste descritivo quantitativo. Foram rejeitados pães contendo 30 e $40 \%$ de polpa úmida, quantias estas superiores às adicionadas nas formulações de biscoitos desenvolvidas neste trabalho.

Biscoitos compostos de amido de mandioca, polpa de peixe desidratada, açúcar, sal e condimentos foram desenvolvidos na Faculdade de Saúde Pública da USP e testados nos laboratórios do Instituto de Pesca em Santos por 40 adultos, obtendo aceitação de $90 \%$ para o biscoito assado em micro-ondas e de 97\%, para o frito (NEIVA, 2008).

O custo dos biscoitos (1,43 real/200 g) não teve diferenças entre os formulados. Se calculados esses custos em função dos preços de fornecedores das matérias-primas utilizadas em processos industriais padronizados, provavelmente esses custos seriam menores.

Sendo um dos objetivos da indústria pesqueira maximizar o aproveitamento do pescado para o consumo humano e considerando os resultados obtidos por Centenaro et al. (2003), a tecnologia caseira proposta poderia ser estudada para sua aplicação em nível industrial, como alternativa barata de uso de carne desidratada proveniente de pescados de espécies subutilizadas, de baixo valor comercial, assim como de aparas de filetagem ou de carne de pescado mecanicamente separada.
$\mathrm{O}$ uso de carne de pescado desidratada, além de facilitar a incorporação dessa matéria-prima à massa (CENTENARO et al., 2003), melhora as condições de armazenamento e transporte da mesma até as fábricas de elaboração dos biscoitos.

A avaliação de vida-de-prateleira tanto da massa ou da polpa de pescado (úmida ou seca) quanto dos biscoitos propostos é necessária.

\section{Conclusões}

- A elaboração de biscoitos com carne de pescado como opção para enriquecer o valor nutricional do produto foi considerada tecnologicamente viável em nível caseiro, além de apresentar características químicas, microbiológicas e sensoriais satisfatórias;

- O menor aporte energético da porção sugerida dos biscoitos formulados com merluza - cujas proteínas possuem maior grau de digestibilidade e valor biológico -, o aumento do conteúdo de minerais e a benéfica composição lipídica dessa matéria-prima fazem dos biscoitos produzidos uma boa alternativa nutricional para merendas e complemento de lanches;

- Os biscoitos com 22,5\% de carne de merluza na sua formulação tiveram preferência entre os consumidores em relação ao biscoito adicionado com $25 \%$ desse ingrediente; $\mathrm{e}$

- Mostrando diversas formas de utilização e aproveitamento do peixe, pode-se incentivar o consumo desta importante matéria-prima do ponto de vista nutricional.

\section{Referências bibliográficas}

ACORSI, D.M, BEZERRA,J.R.M.V.; BARÃO,M.Z.;RIGO, M. Viabilidade do processamento de biscoitos com farinha de pinhão. Ambiência, v. 5, n. 2, p. 207-212 Maio/Ago. 2009

BÁRZANA, E.; GARIBAY-GARCÍA, M. Production of fish protein concentrates. In: MARTIN, A. M. Fisheries processing: biotechnological applications. London: Chapman\&Hall, 1994. p. 206-222. 
BRASIL. Ministério da Saúde. Secretaria de Vigilância Sanitária. Portaria $\mathrm{n}^{\circ} 451$ de 19 de setembro de 1997. Diário Oficial da República Federativa do Brasil, Brasília, DF, 16 jan 1998.

BRASIL. Ministério da Saúde. Agência Nacional de Vigilância Sanitária - Anvisa; INSTITUTO ADOLFO LUTZ. Métodos químicos e físicos para análise de alimentos. 4. ed. Brasília: Ministério da Saúde, 2005. 1018 p. (Série A. Normas e Manuais técnicos).

BRASIL. Ministério da Saúde. Guia alimentar para a população brasileira: promovendo a alimentação saudável. Brasília: Ministério da Saúde, 2006. (Série A. Normas e Manuais técnicos). Disponível em:<http://www.sonutricao.com.br/downloads/Guia_Alimentar_ Populacao_Brasileira.pdf $>$ Acesso em: 10 out. 2008.

CENTENARO, G. S. et al . Enriquecimento de pão com proteínas de pescado. Ciência e Tecnologia de Alimentos, v. 27, n. 3, 2007. Disponível em: <http://www.scielo.br/scielo.php?script=sci_ arttext\&pid=S0101-20612007000300036\&lng=pt\&nrm=iso $>$. Acesso em: 13 dez 2008.

FOOD AND AGRICULTURE ORGANIZATION OF THE UNITED NATIONS - FAO. Norma para galletas de pescado marino y de agua dulce y de mariscos crustáceos y moluscos. 2001. (Codex Stan 222). Disponível em: <http://www.fao.org/docrep/>. Acesso em: 20 set. 2007

GARCIA, R. W. D. Reflexos da globalização na cultura alimentar: considerações sobre as mudanças na alimentação urbana. Revista de Nutrição, v. 16, n. 4, p. 483-492, 2003. http://dx.doi.org/10.1590/ S1415-5273200300040001

GUILHERME, F. F. P.; JOKL, L. Emprego de fubá de melhor qualidade protéica em farinhas mistas para produção de biscoitos. Ciência e Tecnologia de Alimentos, v. 25, n. 1, p. 63-71, 2005. http://dx.doi. org/10.1590/S0101-20612005000100011

HALL, G. M. Fish Processing Technology. New York: VCH Publishers, 1992.

MEILGAARD, M.; CIVILLE,G.V.; CARR, B.T. Sensory Evaluation Techniques. 2.ed. Florida - USA: CRC Press, 1991

NEIVA, C.R.P. Valor Agregado e Qualidade do Pescado. "Simpósio de Controle do Pescado: Qualidade e Sustentabilidade”. Março, 2005. Disponível em ftp//ftp.sp.gov.br/ftppesca/cristiane.pdf. Acesso em 19 set. 2007.

NEIVA, C. R. P. Instituto de Pesca desenvolve alimentos adequados para refeições em instituições. 2008. Disponível em: <http://www. saopaulo.sp.gov.br/spnoticias/lenoticia.php?id=97688> . Acesso em: 27 dez. 2008.

PEREZ, P. M. P.; GERMANI, R. Elaboração de biscoitos tipo salgado, com alto teor de fibra alimentar, utilizando farinha de berinjela (Solanum melongena, L.). Ciência e Tecnologia de Alimentos, Campinas, v. 27, n. 1, p. 186-192, 2007.
POMPEU, R. Campanha de incentivo ao consumo de pescado coincide com a Semana Santa. Agência Brasil, Empresa Brasil de Comunicação, 2008. Disponível em: <http://www.agenciabrasil. gov.br/noticias/2008/01/17/materia.2008-01-17.3812450494/view>. Acesso em: 10 jul. 2008.

RANKEN, M. D. Manual de Industrias de los Alimentos. 2. ed. Zaragoza: Editorial Acribia, S.A., 1993

REIS, J. S. O Brasil já é o segundo maior produtor mundial de biscoitos. Global 21, 2008. Disponível em: <http://www.global21. com.br/entrevistas/entrevista.asp?cod=311>. Acesso em: 10 jul. 2008.

REIS, J. S. Mercado de biscoitos cresce 2,5\% em 2009. Revista Online Brasil Alimentos, 2009. Disponível em: <http://www. brasilalimentos.com.br/neg\%C3\%B3cios/2009/mercado-debiscoitos-cresce-25-em-2009>. Acesso em: 10 jan. 2010.

RODRIGUES, P. Campanha da Semana do Peixe tenta estimular consumo regular de pescado no país. Agência Brasil, Empresa Brasil de Comunicação, 2007. Disponível em: <http://www.agenciabrasil. gov.br/noticias/2007/09/17/materia.2007-09-17.4463399570>. Acesso em: 10 jul. 2008.

SÃO PAULO (Estado). Secretaria da Justiça e da Defesa da Cidadania. Pescados congelados. Disponível em: <http://www.justica.sp.gov. br/Resultado.asp>. Acesso em: 20 set. 2007.

SIMÕES, D. R. S. et al . Desodorização de base protéica de pescado (BPP) com ácido fosfórico. Ciência e Tecnologia de Alimentos, v. 24 , n. 1, p. 23-26, 2004. http://dx.doi.org/10.1590/S010120612004000100005

SUZUKI, T. Tecnología de las Proteínas de Pescado y Krill. Zaragoza: Editorial Acribia, S.A., 1987.

VANDERVANT, C.; SPLIPPSPOESSER, D. F. Compedium of Methods for Microbiological Examination of Foods. 3th ed. American Public Health Association, 1992.

UNIVERSIDADE DE CAMPINAS - UNICAMP. Tabela brasileira de composição de alimentos - TACO. Versão 2. 2. ed. Campinas: UNICAMP/NEPA, 2006.

VARGAS, D. S. T.; QUINTAES, K. D. Potencial perigo microbiológico resultante do uso de caixas plásticas tipo monobloco, no armazenamento e transporte de pescados em São Paulo. Ciência e Tecnologia de Alimentos, v. 23, n. 3, p. 517-522, 2003. http:// dx.doi.org/10.1590/S0101-20612003000300036

VILA NOVA, C.M.V.M; GODOY, H.T; ALDRIGUE, M.L. Composição química, teor de colesterol e caracterização dos lipídios totais de tilápia (Oreochromis niloticus) e pargo (Lutjanus purpureus). Ciência e Tecnologia de Alimentos, v. 25, n. 3, p. 430-436, 2005. http://dx.doi.org/10.1590/S0101-20612005000300007 